\title{
Crystallization Behavior and Thermal Analysis of CoFeB Thin Films
}

\author{
Jiun-Yi Tseng, ${ }^{1}$ Yuan-Tsung Chen, ${ }^{2}$ Z. G. Chang, ${ }^{3}$ C. W. Wu, ${ }^{3}$ and L. C. Yang ${ }^{3}$ \\ ${ }^{1}$ Department of Materials Science and Engineering, National Tsing-Hua University, Hsinchu 30013, Taiwan \\ ${ }^{2}$ Graduate School of Materials Science, National Yunlin University of Science and Technology, 123 University Road, \\ Section 3, Douliou, Yunlin 64002, Taiwan \\ ${ }^{3}$ Department of Materials Science and Engineering, I-Shou University, Kaohsiung 840, Taiwan
}

Correspondence should be addressed to Yuan-Tsung Chen; ytchen@yuntech.edu.tw

Received 24 February 2015; Revised 22 April 2015; Accepted 28 April 2015

Academic Editor: Hongbin Bei

Copyright (C) 2015 Jiun-Yi Tseng et al. This is an open access article distributed under the Creative Commons Attribution License, which permits unrestricted use, distribution, and reproduction in any medium, provided the original work is properly cited.

\begin{abstract}
We examined two targets containing $\mathrm{Co}_{40} \mathrm{Fe}_{40} \mathrm{~B}_{20}$ and $\mathrm{Co}_{60} \mathrm{Fe}_{20} \mathrm{~B}_{20}$. We deposited $\mathrm{Co}_{40} \mathrm{Fe}_{40} \mathrm{~B}_{20}$ and $\mathrm{Co}_{60} \mathrm{Fe}_{20} \mathrm{~B}_{20}$ monolayer thin films of various thicknesses on glass substrates through DC magnetron sputtering; the thicknesses ranged from 25 to $200 \AA$. The thermal properties of the $\mathrm{Co}_{40} \mathrm{Fe}_{40} \mathrm{~B}_{20}$ and $\mathrm{Co}_{60} \mathrm{Fe}_{20} \mathrm{~B}_{20}$ thin films were determined using a differential scanning calorimeter (DSC). The thermal properties included the glass transition temperature $\left(T_{g}\right)$, onset crystallization temperature $\left(T_{x}\right)$, and glass-forming ability, which were determined according to these values. Using the Kissinger formula revealed that the activation energy of the $\mathrm{Co}_{60} \mathrm{Fe}_{20} \mathrm{~B}_{20}$ with a thickness of $75 \AA$ is the highest, implying that crystallization was the lowest and the $\mathrm{Co}_{60} \mathrm{Fe}_{20} \mathrm{~B}_{20}$ film showed anticrystallization properties. However, the energy of $75 \AA \mathrm{Co}_{40} \mathrm{Fe}_{40} \mathrm{~B}_{20}$ thin films was the lowest, which is opposite to that of $\mathrm{Co}_{60} \mathrm{Fe}_{20} \mathrm{~B}_{20}$. This observation can be reasonably explained based on the concentration of Co or Fe. Therefore, a thickness of $75 \AA$ is critical.
\end{abstract}

\section{Introduction}

In recent years, amorphous $\mathrm{CoFeB}$ has been found to have characteristics that can be exploited in scientific research and engineering applications, such as magnetic recording media, magnetoresistance random access memory (MRAM), and gauge sensors. $\mathrm{CoFeB}$ thin films with thicknesses in the range $10-50 \AA$ are used in magnetoresistance (MR) devices, and annealed $\mathrm{CoFeB}$ thin films exhibit perpendicular or inplane anisotropy and B diffusion [1-4]. CoFeB thin films demonstrate excellent magnetic and electrical properties because of their amorphous structure and high spin polarization. An as-deposited ferromagnetic $\mathrm{CoFeB}$ thin film is typically inserted into a spin-valve structure to form a free/ pinned layer of magnetic tunneling junction (MTJ). The formation of the junction leads to increased tunneling magnetoresistance (TMR) and the development of ferromagnetism (FM)/antiferromagnetism (AFM) exchange-biasing anisotropy, which makes the structure suitable for both magnetoresistance random access memory and gauge sensor applications. The increased TMR and exchange-biasing anisotropy are caused by the mean free path of spin being shorter in amorphous materials compared with that of crystalline materials [5-11]. The concentration ratio of Co affects the stability of the amorphous state [12].

In this study, we investigated the crystalline behavior of amorphous CoFeB thin films through thermal analysis. The thermal characteristics and glass-forming ability (GFA) index of amorphous $\mathrm{CoFeB}$ thin films are worthy of research. The structure of $\mathrm{CoFeB}$ films was determined using $\mathrm{X}$ ray diffraction (XRD) patterns. Nonisothermal differential scanning calorimetry (DSC; $T_{A}$ Instruments DSC 2920) was used to determine thermal properties at a heating rate of $20 \mathrm{~K} / \mathrm{min}$. These properties included the glass transition temperature $\left(T_{g}\right)$, onset crystallization temperature $\left(T_{x}\right)$, and liquid temperature $\left(T_{l}\right)$. Crucial related parameters were also measured to estimate the thermal performance, including the range of temperatures at which the film was in the supercooled region $\left(\Delta T_{x}=T_{g}-T_{x}\right)$ and the GFA index, 


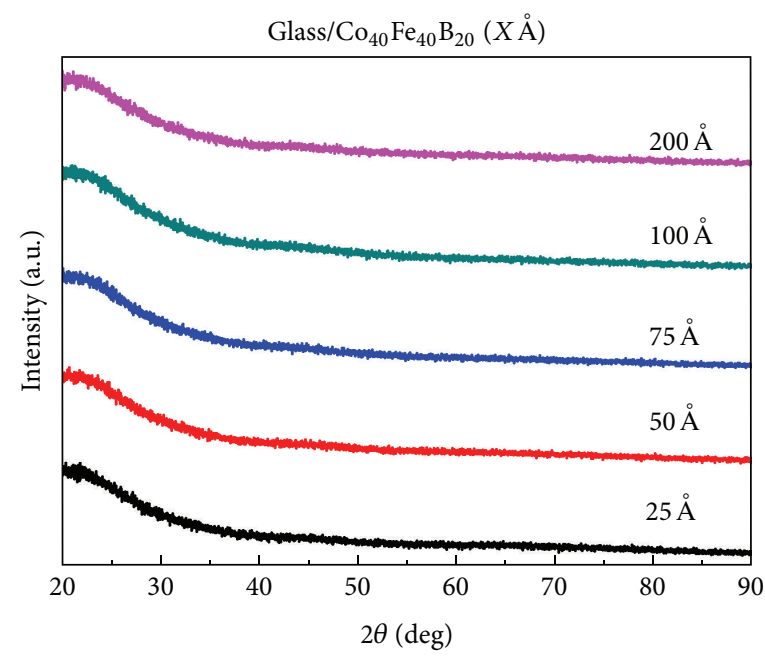

(a)

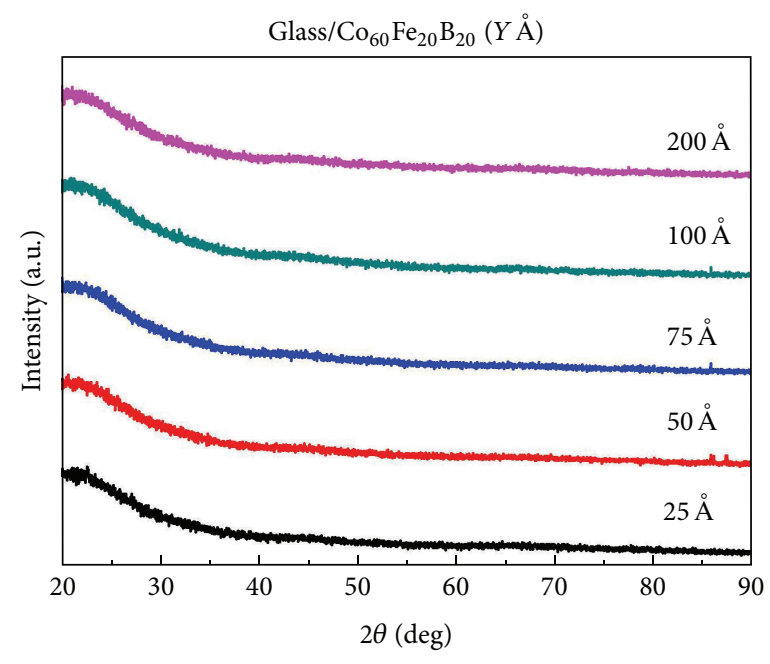

(b)

Figure 1: (a) X-ray diffraction patterns of amorphous $\mathrm{Co}_{40} \mathrm{Fe}_{40} \mathrm{~B}_{20}$ thin films. (b) X-ray diffraction patterns of amorphous $\mathrm{Co}_{60} \mathrm{Fe}_{20} \mathrm{~B}_{20}$ thin films.

which is obtained using $\gamma=T_{x} /\left(T_{g}+T_{l}\right)$ and $\gamma_{m}=$ $\left(2 T_{x}-T_{g}\right) / T_{l}$. To evaluate the resistance to crystallization, the Kissinger formula was used to calculate the activation energy (Q) of crystallization. Thinner $\mathrm{Co}_{40} \mathrm{Fe}_{40} \mathrm{~B}_{20}$ and $\mathrm{Co}_{60} \mathrm{Fe}_{20} \mathrm{~B}_{20}$ films show a higher resistance to crystallization, a wider range of supercooled liquid temperatures, and a higher GFA index because their atomic arrangement is random. This experiment was conducted to improve the atomic crystalline behavior of transformed $\mathrm{Co}_{40} \mathrm{Fe}_{40} \mathrm{~B}_{20}$ and $\mathrm{Co}_{60} \mathrm{Fe}_{20} \mathrm{~B}_{20}$ films.

\section{Experimental Details}

CoFeB thin films were sputtered on a glass substrate by using DC magnetron sputtering at room temperature (RT) to obtain films with thicknesses ranging from 25 to $200 \AA$. The base chamber pressure exceeded $2 \times 10^{-6}$ Torr, and the Ar working pressure was $5 \times 10^{-3}$ Torr. The atomic compositions of the two $\mathrm{CoFeB}$ targets were 60 at \% Co, 20 at \% Fe, and 20 at $\% \mathrm{~B}$ and 40 at \% Co, 40 at \% Fe, and 20 at \% B. XRD with a $\mathrm{CuK}_{\alpha 1}$ line (Philips X'pert) was used to determine the amorphous structure. Thermal performance was investigated using nonisothermal DSC at a heating rate of $20 \mathrm{~K} / \mathrm{min}$. Heating rates in the range $10-40 \mathrm{~K} / \mathrm{min}$ were applied in nonisothermal DSC analysis to determine the crystallization behavior. Several temperatures between $T_{g}$ and $T_{x}$ were applied in isothermal DSC analysis to examine the crystallization kinetics. DSC measurement provides qualitative and quantitative data in endothermic (heat absorbing) and exothermic (heat releasing) processes; nonisothermal and isothermal heating methods can be used to obtain information on changes in physical and/or chemical properties.

\section{Results and Discussion}

Figures 1(a) and 1(b) present the XRD patterns of $\mathrm{Co}_{40} \mathrm{Fe}_{40} \mathrm{~B}_{20}$ and $\mathrm{Co}_{60} \mathrm{Fe}_{20} \mathrm{~B}_{20}$ thin films in the $2 \theta$ range $20^{\circ}-90^{\circ}$. This
$\mathrm{XRD}$ result indicated that the XRD patterns of $\mathrm{Co}_{40} \mathrm{Fe}_{40} \mathrm{~B}_{20}$ and $\mathrm{Co}_{60} \mathrm{Fe}_{20} \mathrm{~B}_{20}$ thin films with thicknesses in the range 25$200 \AA$ were amorphous. Thermal analysis was conducted to examine this phenomenon further (Figures 2(a) and 2(b)).

Figures 2(a) and 2(b) show that the amorphous $\mathrm{Co}_{40} \mathrm{Fe}_{40} \mathrm{~B}_{20}$ and $\mathrm{Co}_{60} \mathrm{Fe}_{20} \mathrm{~B}_{20}$ thin films undergo a change from an amorphous state to a crystalline state through an exothermic crystallization reaction and exhibit a supercooled liquid region in DSC measurements when heated at $40 \mathrm{~K} /$ min. Figure 2 shows that the two CoFeB thin films have a clear glass transition temperature and undergo an exothermic crystallization reaction in the supercooled liquid region.

The corresponding thermal properties of $\mathrm{Co}_{40} \mathrm{Fe}_{40} \mathrm{~B}_{20}$ thin films are shown in Table 1(a), and those of the $\mathrm{Co}_{60} \mathrm{Fe}_{20} \mathrm{~B}_{20}$ thin films are listed in Table $1(\mathrm{~b})$. The evaluated parameters were used to calculate the supercooled liquid region $\left(\Delta T_{x}=T_{g}-T_{x}\right)$, GFA index, and glass transition temperature $\left(T_{r g}=T_{g} / T_{l}, \gamma=T_{x} /\left(T_{g}+T_{l}\right)\right)$ and $\gamma_{m}=$ $\left(2 T_{x}-T_{g}\right) / T_{l}$ [13-15]. The $\gamma$ and $\gamma_{m}$ values of the GFA index indicated that the $\mathrm{Co}_{60} \mathrm{Fe}_{20} \mathrm{~B}_{20}$ thin film with a thickness of $75 \AA$ demonstrated the most effective GFA and showed a high supercooled liquid region $(146 \mathrm{~K})$ and high GFA index $\left(\gamma=0.350\right.$ and $\left.\gamma_{m}=0.586\right)$. The high $\Delta T_{x}$ suggests that the film has high thermal stability. However, $\mathrm{Co}_{40} \mathrm{Fe}_{40} \mathrm{~B}_{20}$ yielded opposite results for the same film thickness. These results suggested that, for CoFeB alloy films, a thickness of $75 \AA$ is critical.

Figures 3(a) and 3(b) show the $Q$ of the crystallization of the CoFeB films, derived using the Kissinger plot [16, 17]:

$$
\ln \left(\frac{\Phi}{T_{p}^{2}}\right)=-\frac{Q}{\mathrm{RT}}+\text { constant }
$$

where $\Phi$ denotes different heating rates in the range 10$40 \mathrm{~K} / \mathrm{min}$ for the nonisothermal DSC analysis performed to determine the crystallization behavior. $R$ is the gas constant and $Q$ is the activation energy. $T$ is the specific measured 


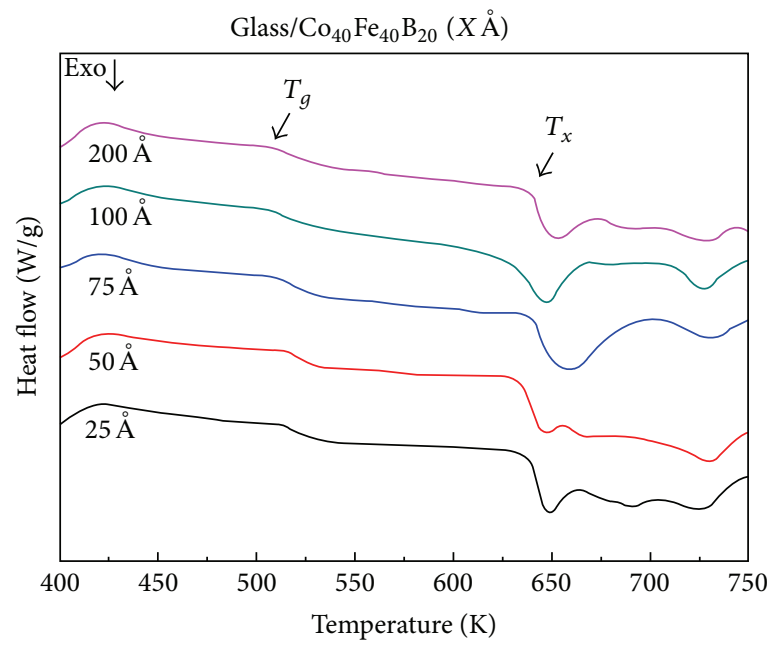

(a)

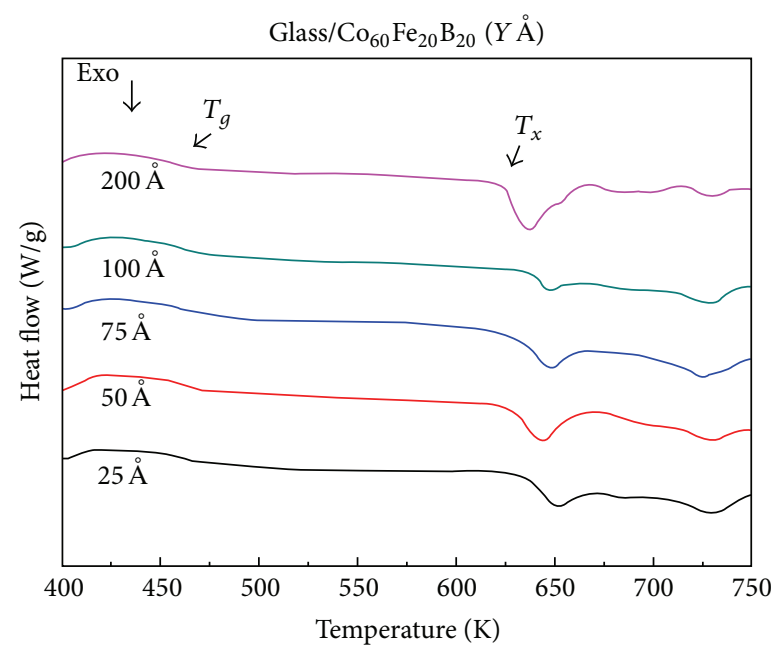

(b)

Figure 2: (a) DSC plots of amorphous $\mathrm{Co}_{40} \mathrm{Fe}_{40} \mathrm{~B}_{20}$ thin films heated at $20 \mathrm{~K} / \mathrm{min}$. (b) DSC plots of amorphous $\mathrm{Co}_{60} \mathrm{Fe}_{20} \mathrm{~B}_{20}$ thin films heated at $20 \mathrm{~K} / \mathrm{min}$.

TABLE 1: (a) Thermal parameters of amorphous $\mathrm{Co}_{40} \mathrm{Fe}_{40} \mathrm{~B}_{20}$ thin films and (b) thermal parameters of amorphous $\mathrm{Co}_{60} \mathrm{Fe}_{20} \mathrm{~B}_{20}$ thin films.

(a)

\begin{tabular}{lccccccc}
\hline $\mathrm{Co}_{40} \mathrm{Fe}_{40} \mathrm{~B}_{20}$ & $T_{g}$ & $T_{x}$ & $\Delta T_{x}$ & $T_{g} / T_{l}$ & $\gamma$ & $\gamma_{m}$ & $\begin{array}{c}Q \\
(\mathrm{~kJ} / \mathrm{mol})\end{array}$ \\
\hline thickness $(\AA)$ & $(\mathrm{K})$ & $(\mathrm{K})$ & $(\mathrm{K})$ & & & & \\
25 & 532 & 635 & 103 & 0.371 & 0.323 & 0.515 & 64.18 \\
50 & 513 & 682 & 169 & 0.358 & 0.351 & 0.594 & 55.01 \\
75 & 499 & 612 & 113 & 0.348 & 0.317 & 0.507 & 45.78 \\
100 & 507 & 622 & 115 & 0.354 & 0.321 & 0.515 & 48.31 \\
200 & 504 & 647 & 143 & 0.352 & 0.334 & 0.551 & 54.44 \\
\hline
\end{tabular}

(b)

\begin{tabular}{lccccccc}
\hline $\begin{array}{l}\mathrm{Co}_{60} \mathrm{Fe}_{20} \mathrm{~B}_{20} \\
\text { thickness }(\AA)\end{array}$ & $\begin{array}{c}T_{g} \\
(\mathrm{~K})\end{array}$ & $\begin{array}{c}T_{x} \\
(\mathrm{~K})\end{array}$ & $\begin{array}{c}\Delta T_{x} \\
(\mathrm{~K})\end{array}$ & $T_{g} / T_{l}$ & $\gamma$ & $\gamma_{m}$ & $\begin{array}{c}Q \\
(\mathrm{~kJ} / \mathrm{mol})\end{array}$ \\
\hline 25 & 546 & 679 & 133 & 0.381 & 0.343 & 0.567 & 55.18 \\
50 & 549 & 673 & 124 & 0.383 & 0.340 & 0.557 & 75.82 \\
75 & 546 & 692 & 146 & 0.381 & 0.350 & 0.586 & 83.44 \\
100 & 553 & 657 & 104 & 0.386 & 0.331 & 0.532 & 80.20 \\
200 & 551 & 691 & 140 & 0.385 & 0.349 & 0.581 & 74.46 \\
\hline
\end{tabular}

temperature of $\mathrm{Co}_{60} \mathrm{Fe}_{20} \mathrm{~B}_{20}$ and $\mathrm{Co}_{40} \mathrm{Fe}_{40} \mathrm{~B}_{20}$ thin films, and $T_{p}$ is the peak temperature of $\mathrm{Co}_{60} \mathrm{Fe}_{20} \mathrm{~B}_{20}$ and $\mathrm{Co}_{40} \mathrm{Fe}_{40} \mathrm{~B}_{20}$ thin films. $1000 / T_{p}$ is easier to fitting data than $1000 / T$. The $Q$ of crystallization was determined according to the slope of a plot of $\ln \left(\Phi / T_{p}^{2}\right)$ as a function of $1 / T$. $Q$ represents the energy barrier that must be overcome before crystallization can occur. A high $Q$ value indicates that transforming the atomic amorphous state to the crystalline state is difficult. By contrast, a low $Q$ value indicates that the atomic amorphous state easily transforms to the crystalline state. The $Q$ values of $\mathrm{Co}_{60} \mathrm{Fe}_{20} \mathrm{~B}_{20}$ thin films were higher than those of $\mathrm{Co}_{40} \mathrm{Fe}_{40} \mathrm{~B}_{20}$ thin films at the film thickness of $75 \AA$.
The Kissinger formula was used to calculate the dependence of the $Q$ of crystallization on the thickness of the $\mathrm{Co}_{40} \mathrm{Fe}_{40} \mathrm{~B}_{20}$ and $\mathrm{Co}_{60} \mathrm{Fe}_{20} \mathrm{~B}_{20}$ films, as shown in Figure 4. The two curves exhibit a cross feature and share a critical thickness of $75 \AA$. These activation energies yielded a critical thickness of $75 \AA$ for amorphous $\mathrm{Co}_{40} \mathrm{Fe}_{40} \mathrm{~B}_{20}$ and $\mathrm{Co}_{60} \mathrm{Fe}_{20} \mathrm{~B}_{20}$ thin films. For the amorphous $\mathrm{Co}_{40} \mathrm{Fe}_{40} \mathrm{~B}_{20}$ film thickness of $75 \AA$, the lowest activation energy was approximately $45.78 \mathrm{~kJ} / \mathrm{mol}$. By contrast, at the same film thickness, the highest activation energy of $\mathrm{Co}_{60} \mathrm{Fe}_{20} \mathrm{~B}_{20}$ was approximately $83.44 \mathrm{~kJ} / \mathrm{mol}$. This result was consistent with the calculated DSC results. A higher activation energy corresponds with a higher resistance to crystallization. The thermal performance of the $\mathrm{Co}_{60} \mathrm{Fe}_{20} \mathrm{~B}_{20}$ thin film was higher than that of the $\mathrm{Co}_{40} \mathrm{Fe}_{40} \mathrm{~B}_{20}$ thin film with various $\mathrm{Co}$ and $\mathrm{Fe}$ concentrations [18-20].

Figures 5(a) and 5(b) show the crystallization fraction as a function of the annealing temperature based on isothermal analysis of Johnson-Mehl-Avrami (JMA) for $75 \AA$ A-thick $\mathrm{Co}_{60} \mathrm{Fe}_{20} \mathrm{~B}_{20}$ and $\mathrm{Co}_{40} \mathrm{Fe}_{40} \mathrm{~B}_{20}$ films [21]. The volume fraction $(x)$ versus time $(t)$ relationship is based on the following equation:

$$
x(t)=1-\exp \left[-(k t)^{n}\right],
$$

where $x$ is the volume fraction transformed as a function of time $t, k$ denotes the rate constant, which is sensitive to temperature because of the dependence of nucleation and growth rates, and $n$ is a dimensionless constant that depends on the combination of nucleation and growth mechanisms for the involved transformation. The volume fraction of crystallization $x$, which is obtained by measuring the partial area under the peak up to time $t$ as a function of annealing time, is illustrated in Figure 5. Because the high annealing temperature thermally induces a high driving force that causes the amorphous structure to become crystalline, the duration of the high annealing temperature is shorter than 

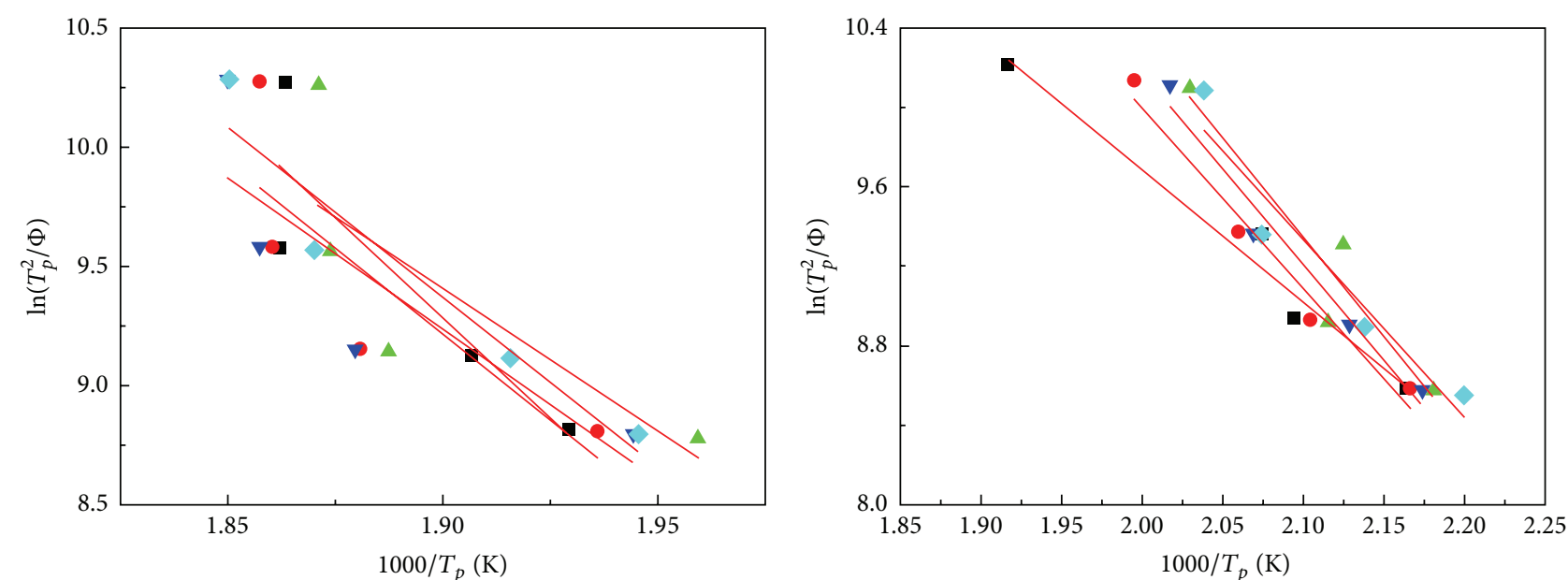

Thickness
$(\AA)$
- 25
- 50
$>75$
V 100
$>200$

Activation energy

$(\mathrm{kJ} / \mathrm{mole})$

$64.18 \pm 6$

$55.01 \pm 7$

$45.78 \pm 7$

$48.31 \pm 6$

$54.44 \pm 3$

(a)

$\begin{array}{lc}\begin{array}{l}\text { Thickness of thin film } \\ (\AA)\end{array} & \begin{array}{c}\text { Activation energy } \\ (\mathrm{kJ} / \text { mole })\end{array} \\ \text { - } 25 & 55.18 \pm 2 \\ \text { - } 50 & 75.82 \pm 3 \\ \text { A } 75 & 83.44 \pm 5 \\ \text { V } 100 & 80.20 \pm 3 \\ >200 & 74.46 \pm 4\end{array}$

(b)

Figure 3: (a) Kissinger plot of DSC peaks for crystallization of amorphous $\mathrm{Co}_{40} \mathrm{Fe}_{40} \mathrm{~B}_{20}$ thin films. (b) Kissinger plot of DSC peaks for crystallization of amorphous $\mathrm{Co}_{60} \mathrm{Fe}_{20} \mathrm{~B}_{20}$ thin films.

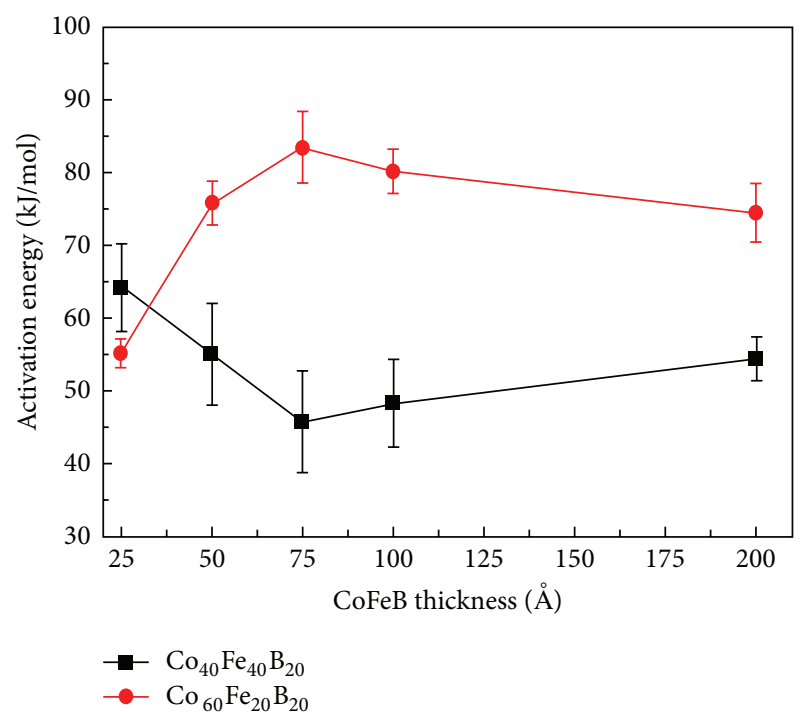

FIGURE 4: Activation energy of crystallization process, estimated from Kissinger fitting for amorphous $\mathrm{Co}_{40} \mathrm{Fe}_{40} \mathrm{~B}_{20}$ and $\mathrm{Co}_{60} \mathrm{Fe}_{20} \mathrm{~B}_{20}$ thin films with various thicknesses.

that of the low annealing temperature. Based on the crystallization fraction from $0 \%$ to $100 \%$, the annealing time of the $75 \AA$-thick $\mathrm{Co}_{60} \mathrm{Fe}_{20} \mathrm{~B}_{20}$ thin film is longer than that of the $75 \AA$-thick $\mathrm{Co}_{40} \mathrm{Fe}_{40} \mathrm{~B}_{20}$ thin film.

The incubation time of the $75 \AA$-thick $\mathrm{Co}_{60} \mathrm{Fe}_{20} \mathrm{~B}_{20}$ thin film as a function of the isothermal annealing temperature revealed a longer time than that of the $\mathrm{Co}_{40} \mathrm{Fe}_{40} \mathrm{~B}_{20}$ thin film, as shown in Figure 6. This demonstrates that the thermal stability of $\mathrm{Co}_{60} \mathrm{Fe}_{20} \mathrm{~B}_{20}$ films is higher than that of the $\mathrm{Co}_{40} \mathrm{Fe}_{40} \mathrm{~B}_{20}$ films in isothermal analysis. According to results of DSC and Kissinger formula, the $75 \AA$-thick is a critical and important point in $\mathrm{Co}_{60} \mathrm{Fe}_{20} \mathrm{~B}_{20}$ and $\mathrm{Co}_{40} \mathrm{Fe}_{40} \mathrm{~B}_{20}$ thin films. The $75 \AA$-thick $\mathrm{Co}_{60} \mathrm{Fe}_{20} \mathrm{~B}_{20}$ thin film has the highest activation energy. In contrast, the $75 \AA$-thick $\mathrm{Co}_{40} \mathrm{Fe}_{40} \mathrm{~B}_{20}$ thin film has the lowest activation energy. Figures 5 and 6 investigated the crystallization fraction and incubation time to prove that the thermal stability of $\mathrm{Co}_{60} \mathrm{Fe}_{20} \mathrm{~B}_{20}$ thin film is stronger than $\mathrm{Co}_{40} \mathrm{Fe}_{40} \mathrm{~B}_{20}$ thin film.

\section{Conclusions}

In summary, the thermal performance, crystallization behavior, calculated anticrystallization, and structure of $\mathrm{Co}_{40} \mathrm{Fe}_{40} \mathrm{~B}_{20}$ and $\mathrm{Co}_{60} \mathrm{Fe}_{20} \mathrm{~B}_{20}$ thin films were investigated using DSC, XRD, and the Kissinger fitting method. The GFA index, defined using $\gamma$ and $\gamma_{m}$, increased as the thickness decreased. Moreover, the Kissinger fitting indicated that the critical thickness of the $\mathrm{CoFeB}$ thin film was $75 \AA$. The performance of $\mathrm{Co}_{60} \mathrm{Fe}_{20} \mathrm{~B}_{20}$ thin films is more suitable for amorphous magnetic thin-film applications because of a high GFA index, $Q$, and $\Delta T_{x}$. A critical result is that amorphous $\mathrm{CoFeB}$ thin films can be used in the magnetic recording industry and crystalline applications because of their crystalline behavior. Finally, based on the nonisothermal and isothermal analyses, the thermal stability and incubation time of $\mathrm{Co}_{60} \mathrm{Fe}_{20} \mathrm{~B}_{20}$ films were more favorable than those of $\mathrm{Co}_{40} \mathrm{Fe}_{40} \mathrm{~B}_{20}$ films. 


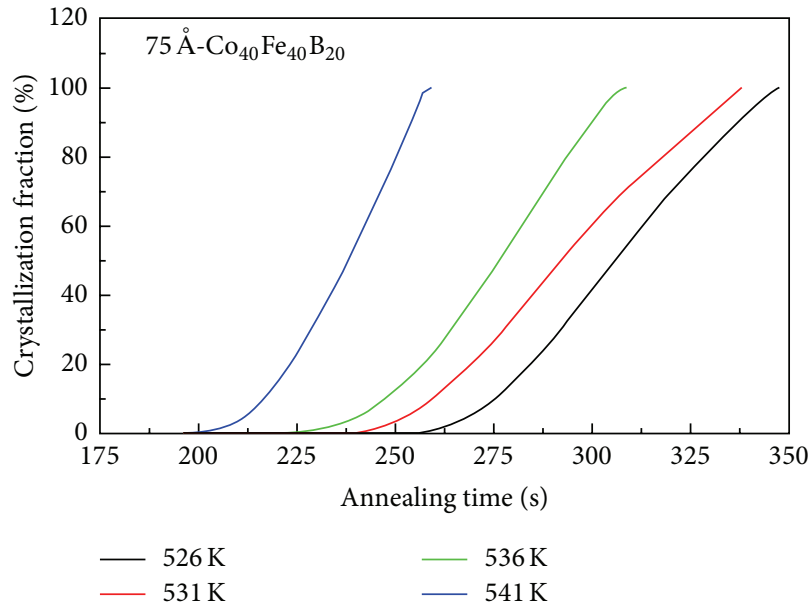

(a)

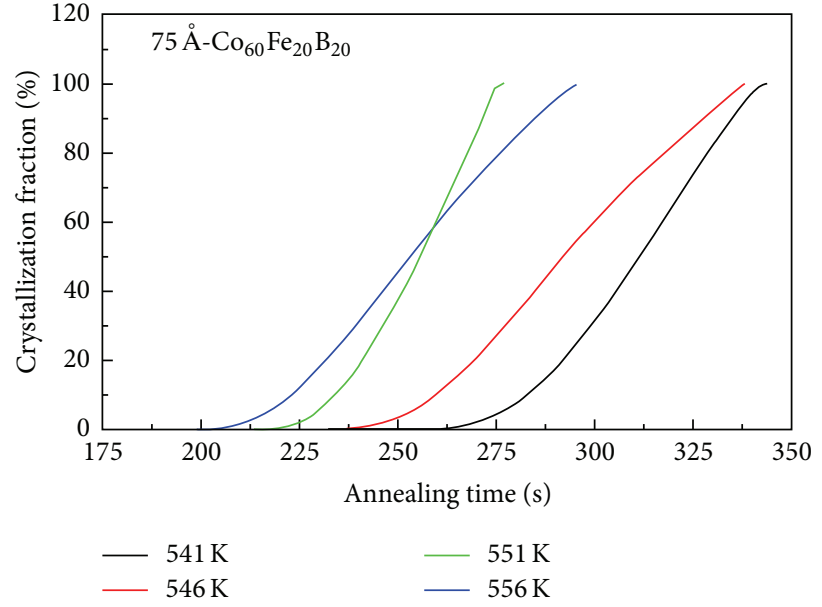

(b)

Figure 5: Crystallization fraction as a function of annealing time with various thicknesses. (a) Amorphous $75 \AA$-thick $\mathrm{Co}_{40} \mathrm{Fe}_{40} \mathrm{~B}_{20}$ thin film and (b) amorphous $75 \AA$-thick $\mathrm{Co}_{60} \mathrm{Fe}_{20} \mathrm{~B}_{20}$ thin film.

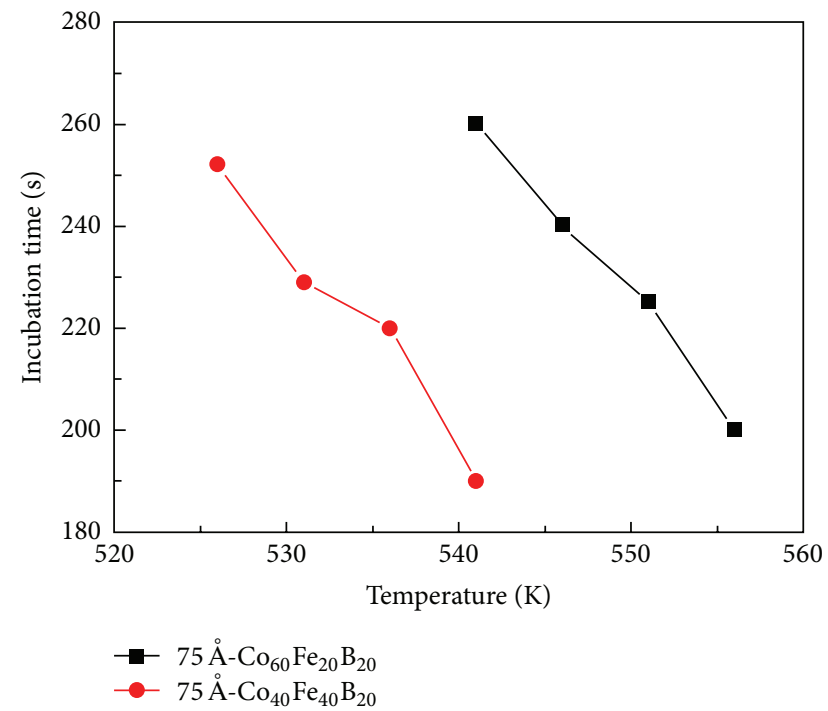

Figure 6: Incubation time of $75 \AA$-thick $\mathrm{Co}_{40} \mathrm{Fe}_{40} \mathrm{~B}_{20}$ thin film and $75 \AA$-thick $\mathrm{Co}_{60} \mathrm{Fe}_{20} \mathrm{~B}_{20}$ thin film as a function of isothermal annealing temperature.

\section{Conflict of Interests}

The authors declare that there is no conflict of interests regarding the publication of this paper.

\section{Acknowledgments}

This work was supported by the Ministry of Science and Technology, under Grant no. MOST103-2112-M-224-002. The authors also would like to acknowledge the help on XRD analysis by the Micro and Nano Analysis Laboratory of IShou University.

\section{References}

[1] S. Ikeda, K. Miura, H. Yamamoto et al., "A perpendicular-anisotropy CoFeB-MgO magnetic tunnel junction," Nature Materials, vol. 9, no. 9, pp. 721-724, 2010.

[2] C. Y. You, H. S. Goripati, T. Furubayashi, Y. K. Takahashi, and K. Hono, "Exchange bias of spin valve structure with a top-pinned $\mathrm{Co}_{40} \mathrm{Fe}_{40} \mathrm{~B}_{20} / \mathrm{IrMn}$," Applied Physics Letters, vol. 93, no. 1, Article ID 012501, 2008.

[3] W. X. Wang, Y. Yang, H. Naganuma, Y. Ando, R. C. Yu, and X. F. Han, "The perpendicular anisotropy of $\mathrm{Co}_{40} \mathrm{Fe}_{40} \mathrm{~B}_{20}$ sandwiched between $\mathrm{Ta}$ and $\mathrm{MgO}$ layers and its application in $\mathrm{CoFeB} / \mathrm{MgO} / \mathrm{CoFeB}$ tunnel junction," Applied Physics Letters, vol. 99, no. 1, Article ID 012502, 2011.

[4] Y. Yang, W. X. Wang, Y. Yao et al., "Chemical diffusion: another factor affecting the magnetoresistance ratio in $\mathrm{Ta} / \mathrm{CoFeB} / \mathrm{MgO} /$ $\mathrm{CoFeB} / \mathrm{Ta}$ magnetic tunnel junction," Applied Physics Letters, vol. 101, no. 1, Article ID 012406, 3 pages, 2012.

[5] Y. Nagamine, H. Maehara, K. Tsunekawa et al., "Ultralow resistance-area product of $0.4 \Omega(\mu \mathrm{m})^{2}$ and high magnetoresistance above $50 \%$ in $\mathrm{CoFe} / \mathrm{B} / \mathrm{MgO} / \mathrm{CoFeB}$ magnetic tunnel junctions," Applied Physics Letters, vol. 89, no. 16, Article ID 162507, 2006.

[6] J. Hayakawa, S. Ikeda, Y. M. Lee et al., "Current-driven magnetization switching in $\mathrm{CoFeB} / \mathrm{MgO} / \mathrm{CoFeB}$ magnetic tunnel junctions," Japanese Journal of Applied Physics, vol. 44, no. 3741, pp. L1267-L1270, 2005.

[7] Y. T. Chen and Z. G. Chang, "Low-frequency alternativecurrent magnetic susceptibility of amorphous and nanocrystalline $\mathrm{Co}_{60} \mathrm{Fe}_{20} \mathrm{~B}_{20}$ films," Journal of Magnetism and Magnetic Materials, vol. 324, no. 14, pp. 2224-2226, 2012.

[8] Y. M. Lee, J. Hayakawa, S. Ikeda, F. Matsukura, and H. Ohno, "Giant tunnel magnetoresistance and high annealing stability in $\mathrm{CoFeB} / \mathrm{MgO} / \mathrm{CoFeB}$ magnetic tunnel junctions with synthetic pinned layer," Applied Physics Letters, vol. 89, no. 4, Article ID 042506, 2006.

[9] C. Y. You, T. Ohkubo, Y. K. Takahashi, and K. Hono, "Boron segregation in crystallized $\mathrm{MgO} /$ amorphous $-\mathrm{Co}_{40} \mathrm{Fe}_{40} \mathrm{~B}_{20}$ thin 
films," Journal of Applied Physics, vol. 104, no. 3, Article ID 033517, 2008.

[10] T. Aoki, Y. Ando, D. Watanabe, M. Oogane, and T. Miyazaki, "Spin transfer switching in the nanosecond regime for $\mathrm{CoFeB} /$ $\mathrm{MgO} / \mathrm{CoFeB}$ ferromagnetic tunnel junctions," Journal of Applied Physics, vol. 103, no. 10, Article ID 103911, 2008.

[11] D. H. Lee and S. H. Lim, "Increase of temperature due to Joule heating during current-induced magnetization switching of an MgO-based magnetic tunnel junction," Applied Physics Letters, vol. 92, no. 23, Article ID 233502, 3 pages, 2008.

[12] A. Gupta, K. Ruwali, N. Paul, and P. Duhaj, "Crystallization behaviour of amorphous $\left(\mathrm{Fe}_{100-x} \mathrm{Co}_{x}\right)_{85} \mathrm{~B}_{15}$," Materials Science and Engineering A, vol. 304-306, no. 1-2, pp. 371-374, 2001.

[13] J. S. C. Jang, C. F. Chang, Y. C. Huang, J. C. Huang, W. J. Chiang, and C. T. Liu, "Viscous flow and microforming of a Zr-base bulk metallic glass," Intermetallics, vol. 17, no. 4, pp. 200-204, 2009.

[14] C. J. Gilbert, J. M. Lippmann, and R. O. Ritchie, "Fatigue of a Zr-Ti-Cu-Ni-Be bulk amorphous metal: stress/life and crackgrowth behavior," Scripta Materialia, vol. 38, no. 4, pp. 537-542, 1998.

[15] A. Inoue, B. Shen, H. Koshiba, H. Kato, and A. R. Yavari, "Cobalt-based bulk glassy alloy with ultrahigh strength and soft magnetic properties," Nature Materials, vol. 2, no. 10, pp. 661663, 2003.

[16] J. S. C. Jang, S. R. Jian, D. J. Pan, Y. H. Wu, J. C. Huang, and T. G. Nieh, "Thermal and mechanical characterizations of a Zr-based bulk metallic glass composite toughened by in-situ precipitated Ta-rich particles," Intermetallics, vol. 18, no. 4, pp. 560-564, 2010.

[17] H. E. Kissinger, "Reaction kinetics in differential thermal analysis," Analytical Chemistry, vol. 29, no. 11, pp. 1702-1706, 1957.

[18] J. Park and H. Yim, "Designing the composition of amorphous free layer of a magnetic tunnel junction," IEEE Transactions on Magnetics, vol. 45, no. 6, pp. 2413-2416, 2009.

[19] W. L. Johnson, "Bulk glass-forming metallic alloys: science and technology," MRS Bulletin, vol. 24, no. 10, pp. 42-56, 1999.

[20] W. S. Sun, X. B. Liang, and T. Kulik, "Formation and magnetic properties of Co-Fe-based bulk metallic glasses with supercooled liquid region," Journal of Magnetism and Magnetic Materials, vol. 299, no. 2, pp. 492-495, 2006.

[21] A. Hsiao, M. E. McHenry, D. E. Laughlin, M. J. Kramer, C. Ashe, and T. Ohkubo, "The thermal, magnetic, and structural characterization of the crystallization kinetics of $\mathrm{Fe}_{88} \mathrm{Zr}_{7} \mathrm{~B}_{4} \mathrm{Cu}_{1}$, an amorphous soft magnetic ribbon," IEEE Transactions on Magnetics, vol. 38, no. 5, pp. 3039-3044, 2002. 

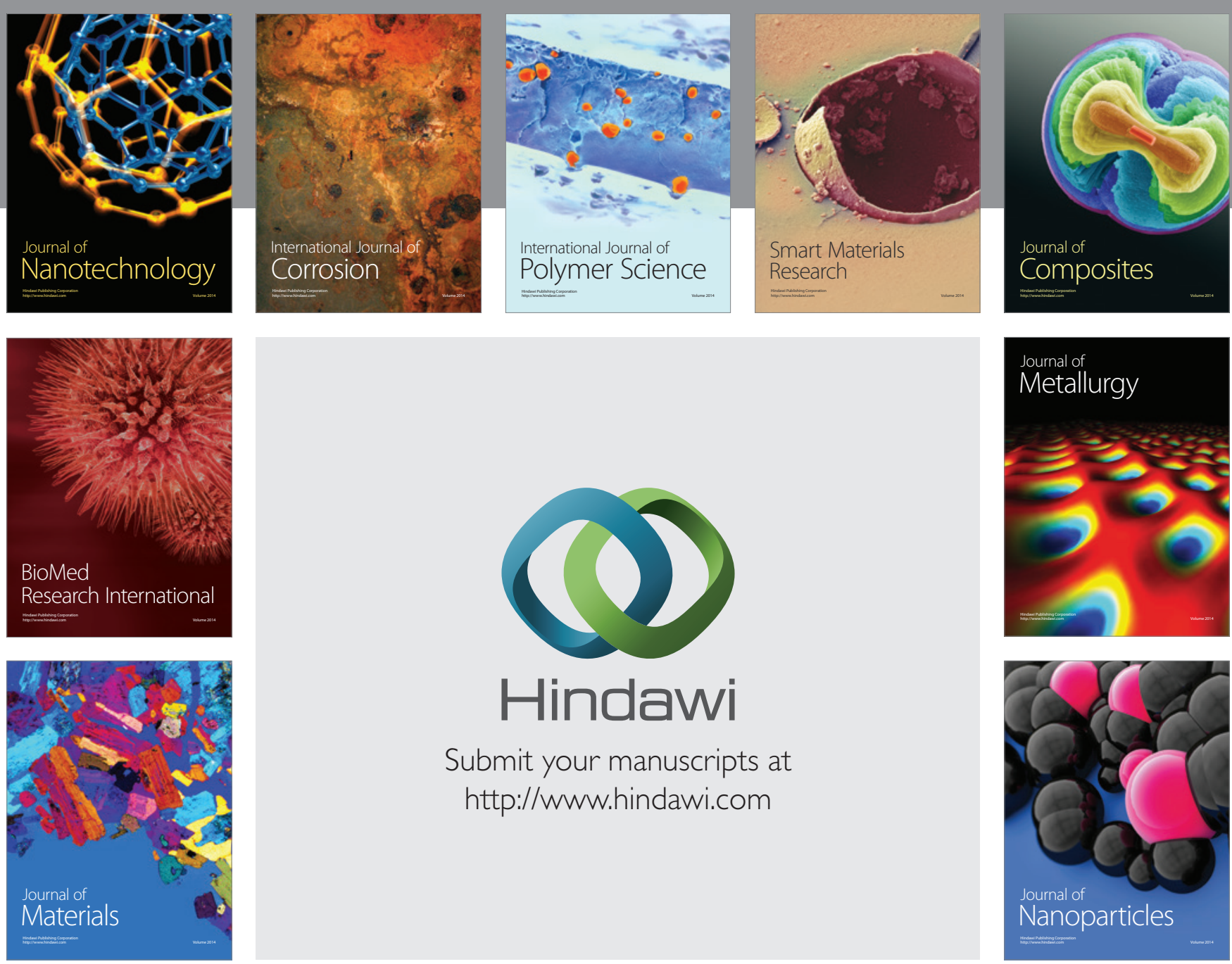

Submit your manuscripts at http://www.hindawi.com
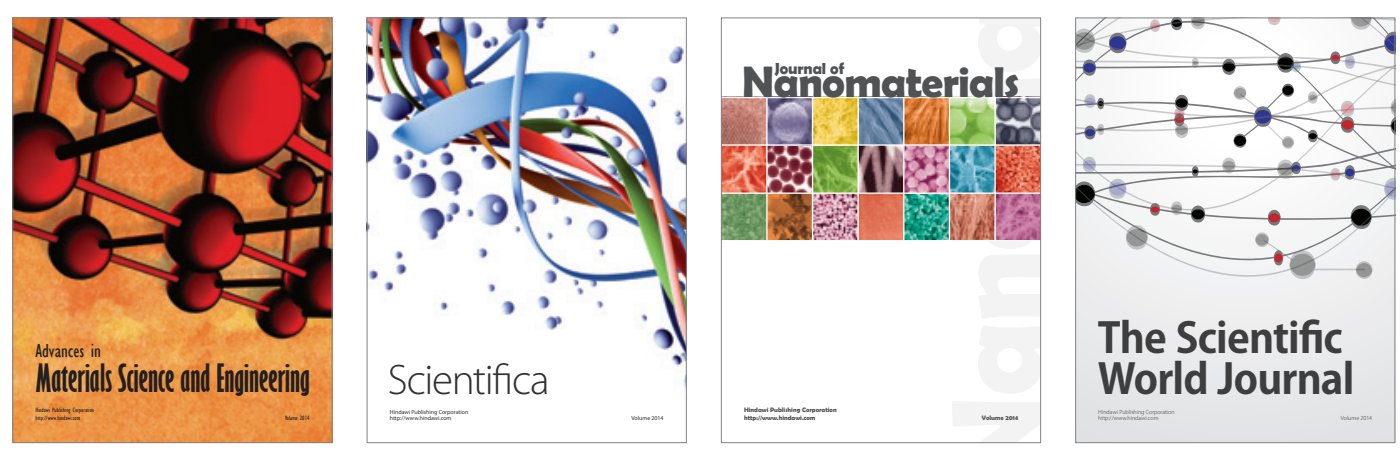

\section{The Scientific World Journal}
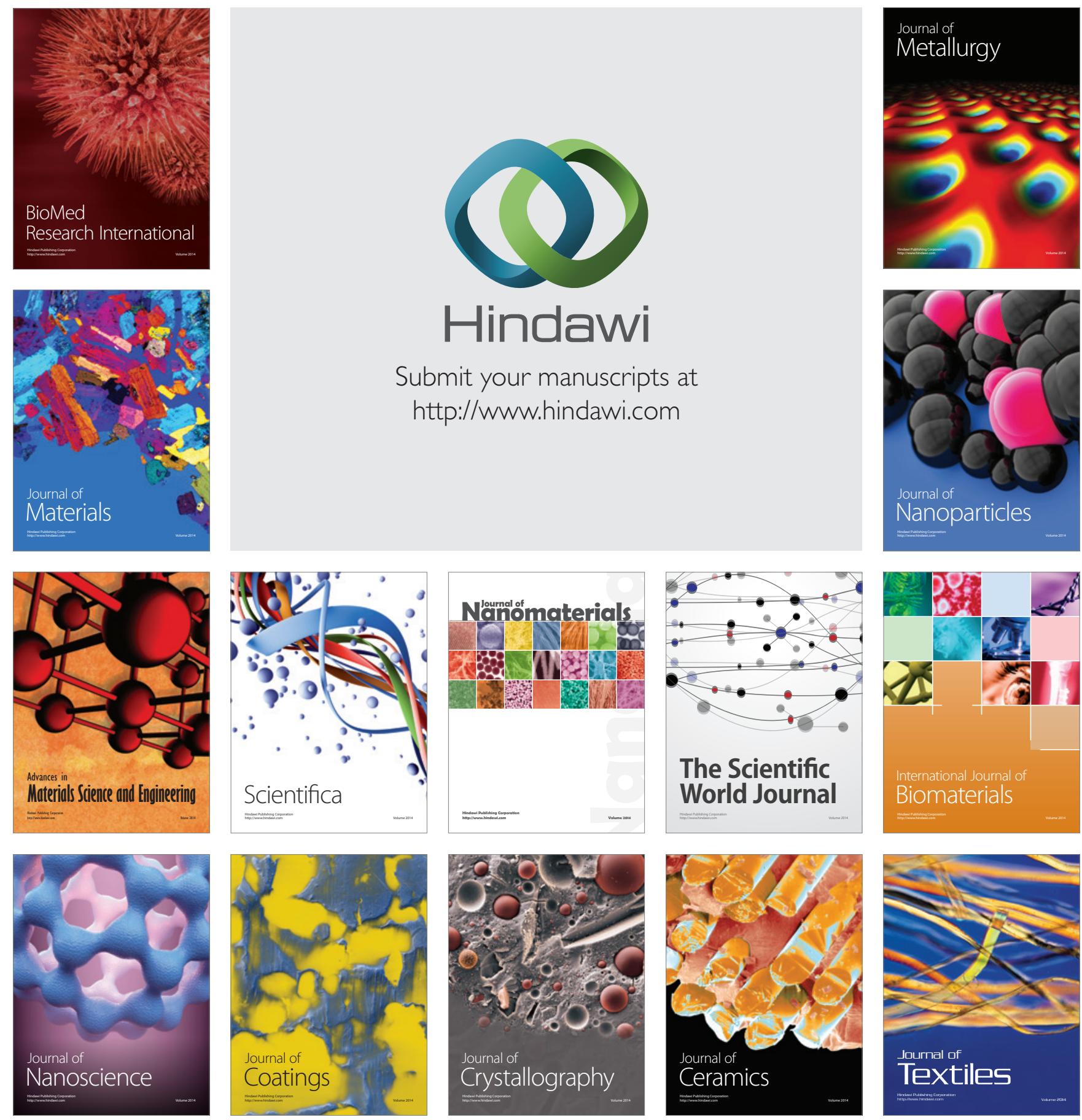